\title{
Morphology and Molecular Phylogeny of Raillietina spp. (Cestoda: Cyclophyllidea: Davaineidae) from Domestic Chickens in Thailand
}

\author{
Preeyaporn Butboonchoo', Chalobol Wongsawad ${ }^{1,2 ;}$, Amnat Rojanapaibul', Jong-Yil Chaii, \\ 'Department of Biology, Faculty of Science, Chiang Mai University, ${ }^{2}$ The Applied Technology for Biodiversity Research Unit, Science and Technology \\ Research Institute, Chiang Mai University, Chiang Mai 50200, Thailand; ' ${ }^{2}$ Department of Parasitology and Tropical Medicine, Seoul National University \\ College of Medicine, Seoul 03080, Korea; ${ }^{4}$ Institute of Parasitic Diseases, Korea Association of Health Promotion, Seoul 07649, Korea
}

\begin{abstract}
Raillietina species are prevalent in domestic chickens (Gallus gallus domesticus) in Phayao province, northern Thailand. Their infection may cause disease and death, which affects the public health and economic situation in chicken farms. The identification of Raillietina has been based on morphology and molecular analysis. In this study, morphological observations using light (LM) and scanning electron microscopies (SEM) coupled with molecular analysis of the internal transcribed spacer 2 (ITS2) region and the nicotinamide adenine dinucleotide dehydrogenase subunit 1 (ND1) gene were employed for precise identification and phylogenetic relationship studies of Raillietina spp. Four Raillietina species, including $R$. echinobothrida, $R$. tetragona, $R$. cesticillus, and Raillietina sp., were recovered in domestic chickens from 4 districts in Phayao province, Thailand. LM and SEM observations revealed differences in the morphology of the scolex, position of the genital pore, number of eggs per egg capsule, and rostellar opening surface structures in all 4 species. Phylogenetic relationships were found among the phylogenetic trees obtained by the maximum likelihood and distance-based neighbor-joining methods. ITS2 and ND1 sequence data recorded from Raillietina sp. appeared to be monophyletic. The query sequences of $R$. echinobothrida, $R$. tetragona, $R$. cesticillus, and Raillietina sp. were separated according to the different morphological characters. This study confirmed that morphological studies combined with molecular analyses can differentiate related species within the genus Raillietina in Thailand.
\end{abstract}

Key words: Raillietina echinobothrida, Raillietina tetragona, Raillietina cesticillus, Raillietina sp., morphology, phylogeny, ITS2, ND1, chicken, Thailand

\section{INTRODUCTION}

Among the davaineid genera, the most common is Raillietina Fuhrmann, 1920 with about 295 species reported from avian and mammalian hosts, including humans [1]. Their infections are highly pathogenic in domestic chickens (Gallus gallus domesticus), for example, in Phayao province [2]. Raillietina species are found in the jejunum and ileum of the definitive host and can cause reduced growth, emaciation, weakness, and digestive tract obstruction [3], whereas their larval stage (cyticercoid) resides in various invertebrate intermediate host, such as ants, beetles, small mini-wasps, or termites [4,5]. The genus Raillietina is divided into 4 subgenera; Raillietina Fuhrmann,

- Received 7 June2016, revised 11 September 2016, accepted 26 September 2016.

*Corresponding author (wchalobol@gmail.com)

(c) 2016, Korean Society for Parasitology and Tropical Medicine

This is an Open Access article distributed under the terms of the Creative Commons Attribution Non-Commercial License (http://creativecommons.org/licenses/by-nc/4.0) which permits unrestricted non-commercial use, distribution, and reproduction in any

medium, provided the original work is properly cited.
1920, Paroniella Fuhrmann, 1920, Skrjabinia Fuhrmann, 1920, and Fuhrmann Fuhrmann, 1920 [1].

The species identification of Raillietina has been based on the morphology and molecular study results. The morphological characters used for distinguishing Raillietina spp. include differences in the size and shape of the scolex, morphology of the rostellum (armed with either a single row or double rows of hooks) and suckers (armed or unarmed), the position (unilateral or irregularly alternating) and number of genital pores per segment, and the number of the eggs within an egg capsule in gravid proglottids $[1,6,7]$. However, the morphological characters of Raillietina spp. show marked variations within and between species. Therefore, it is difficult to identify them only based on the morphology. Instead, molecular approaches, in combination with morphological analyses, became the most effective and accurate method for identification of helminth parasites. With regard to the molecular techniques, conventional PCR and HAT-RAPD have been used to differentiate among Raillietina group obtained from domestic chickens in 
Thailand [2]. However, there are many DNA regions useful for identification of helminths and discrimination between species with similar morphologies. Especially, internal transcribed spacer 2 (ITS2) in nuclear gene and nicotinamide adenine dinucleotide dehydrogenase subunit 1 (ND1) in mitochondrial gene are commonly used because of their high variation rates. In addition, the gene sequences of these locations have been developed for molecular phylogenetic studies [8-11].

In the present study, we examined the ITS2 and ND1 regions to infer the phylogenetic relationships of Raillietina spp. from domestic chickens (Gallus gallus domesticus) in Phayao province, Thailand, in combination with morphological analyses using light (LM) and scanning electron microscopes (SEM).

\section{MATERIALS AND METHODS}

\section{Sample collection}

Live tapeworms (Raillietina spp.) were obtained from the small intestine of naturally infected domestic chickens from 4 districts (Chiang Kham, Chun, Dok Khamtai, and Mae Chai) in Phayao province, Thailand. The specimens were flattened and fixed in $4 \%$ formalin for light microscopic (LM) studies and prefixed in $2.5 \%$ glutaraldehyde for scanning electron microscopic (SEM) studies. For molecular analysis, the specimens were rinsed several times with tape water and then frozen at $-20^{\circ} \mathrm{C}$ immediately for later DNA extraction.

\section{Morphological observations}

For LM observations, the specimens were prepared for permanent slides. All permanent slides of each species were drawn as figures by using a drawing tube. For SEM observations, the specimens were post-fixed with $1 \%$ osmium tetroxide. They were dehydrated in a graded series of ethanol $(10 \%$, $20 \%, 30 \%, 50 \%, 70 \%, 85 \%, 95 \%$, and absolute), then transferred into acetone, and finally dried in a critical-point dryer. The specimens were mounted on stubs, gold-coated, and observed with JEOL-JSM5400LV scanning electron microscope (Tokyo, Japan) at an accelerating voltage of 10-15 kV.

\section{DNA extraction}

Genomic DNA was extracted by using Chelex solution. In brief, $150 \mu \mathrm{l}$ of 5\% Chelex (Fluka) solution containing $10 \mu \mathrm{l}$ of proteinase K (Sigma-Aldrich, St. Louis, Missouri, USA) at a concentration of $20 \mathrm{mg} / \mathrm{ml}$ was added to approximately 20 mg of the cestode tissue. It was then heated to $55^{\circ} \mathrm{C}$ for $1 \mathrm{hr}$, followed by gentle vortexing and heating at $95^{\circ} \mathrm{C}$ for $30 \mathrm{~min}$, again followed by gentle vortexing. The mixture was centrifuged at 13,000 $\mathrm{g}$ for $1 \mathrm{~min}$. The supernatant was collected and stored at $-20^{\circ} \mathrm{C}$ until used.

\section{Amplification of ITS2 region}

The ITS2 region was amplified by using the primers, forward $3 S$ (5'-GGT ACC GGT GGA TCA CTC GGC TCG TG-3') and reverse BD2 (5'-TAT GCT TAA ATT CAG CGG GT-3'). The PCR conditions were as follows: $2 \mathrm{~min}$ initial denaturation at $94^{\circ} \mathrm{C}$, followed by 35 cycles of 1 min DNA denaturation at $94^{\circ} \mathrm{C}, 1$ min primer annealing at $57^{\circ} \mathrm{C}, 1$ min extension at $72^{\circ} \mathrm{C}$, and a final extension at $72^{\circ} \mathrm{C}$ for $7 \mathrm{~min}$.

The amplification product was checked using agarose gel electrophoresis with ethidium bromide staining. All PCR products were purified using Cleanup PCR Kit (Sigma-Aldrich) and were subjected to sequencing.

\section{Amplification of ND1 gene}

The ND1 gene was amplified by using the primers, JB11 (5'AGA TTC GTA AGG GGC CTA ATA - $3^{\prime}$ ) as the forward primer and JB12 (5'-ACC ACT AAC TAA TTC ACT TTC - $3^{\prime}$ ) as the reverse primer. The PCR conditions were as follows: 2 min initial denaturation at $94^{\circ} \mathrm{C}$, followed by 39 cycles of $30 \mathrm{sec}$ DNA denaturation at $94^{\circ} \mathrm{C}, 20 \mathrm{sec}$ primer annealing at $48^{\circ} \mathrm{C}, 1 \mathrm{~min}$ extension at $72^{\circ} \mathrm{C}$, and a final extension at $72^{\circ} \mathrm{C}$ for $10 \mathrm{~min}$.

The amplification product was checked using agarose gel electrophoresis with ethidium bromide staining to visualize the ND1 products. All PCR products were purified using Cleanup PCR Kit (Sigma-Aldrich) and were subjected to sequencing.

\section{Phylogenetic analysis}

Our data sequence, ITS2 product revealed the size of 944 , $1,008,813$ and 588 bp with flanking region of $5.8 \mathrm{~S}$ and $28 \mathrm{~S}$ in R. echinobothrida, R. tetragona, R.cesticillus and Raillietina sp., respectively. For the ND1 product revealed the size of partial sequence of $489 \mathrm{bp}$ in all four species of Raillietina. The data in this study included the sequences from the representative group of Raillietina in GenBank (Tables 1, 2), and then were aligned using ClustalW. The phylogenetic tree was constructed for each gene using MEGA version 6.0 with neighbor-joining (NJ) and maximum-likelihood (ML) methods. The statistics supported for branches were tested using 1,000 bootstrap replicates. 
Table 1. Helminth species used in this study and GenBank accession numbers for their corresponding ITS2 sequence

\begin{tabular}{|c|c|c|c|c|}
\hline Species & Host & Country & GenBank accession no. & Family \\
\hline Raillietina echinobothrida ${ }^{a}$ & Gallus gallus domesticus & Thailand & - & Davaineidae \\
\hline Raillietina tetragona ${ }^{a}$ & Gallus gallus domesticus & Thailand & - & Davaineidae \\
\hline Raillietina cesticillus ${ }^{\mathrm{a}}$ & Gallus gallus domesticus & Thailand & - & Davaineidae \\
\hline Raillietina sp. ${ }^{a}$ & Gallus gallus domesticus & Thailand & - & Davaineidae \\
\hline Raillietina australis & Dromaius novaehollandiae & Australia & AY382317 & Davaineidae \\
\hline Raillietina chiltoni & Dromaius novaehollandiae & Australia & AY382319 & Davaineidae \\
\hline Raillietina beveridgei & Dromaius novaehollandiae & Australia & AY382318 & Davaineidae \\
\hline Raillietina dromaius & Dromaius novaehollandiae & Australia & AY382320 & Davaineidae \\
\hline Taenia saginata & Cattle & China & AY825542 & Taeniidae \\
\hline Taenia pisiformis & Rabbit & China & JX317675 & Taeniidae \\
\hline Taenia hydatigena & Dog & China & FJ886761 & Taeniidae \\
\hline Hymenolepis diminuta & Mouse & Japan & AB494474 & Hymenolepididae \\
\hline Hymenolepis nana & Mouse & Mexico & HM536189 & Hymenolepididae \\
\hline Hymenolepis microstoma & Hmic & Japan & AB494478 & Hymenolepididae \\
\hline Diphyllobothrium nihonkaiense ${ }^{b}$ & Homo sapiens & Japan & AB288369 & Diphyllobothriidae \\
\hline
\end{tabular}

Table 2. Helminth species used in this study and GenBank accession numbers for their corresponding ND1 sequence

\begin{tabular}{|c|c|c|c|c|}
\hline Species & Host & Country & GenBank accession no. & Family \\
\hline Raillietina echinobothrida ${ }^{a}$ & Gallus gallus domesticus & Thailand & - & Davaineidae \\
\hline Raillietina tetragona ${ }^{a}$ & Gallus gallus domesticus & Thailand & - & Davaineidae \\
\hline Raillietina cesticillus ${ }^{a}$ & Gallus gallus domesticus & Thailand & - & Davaineidae \\
\hline Raillietina sp. ${ }^{\text {a }}$ & Gallus gallus domesticus & Thailand & - & Davaineidae \\
\hline Raillietina sonini & Dendrocopos syriacus & Bulgaria & EU665490 & Davaineidae \\
\hline Raillietina sp.3 & Picoides pubescens & USA & EU665489 & Davaineidae \\
\hline Raillietina sp.2 & Picoides villosus & USA & EU665488 & Davaineidae \\
\hline Raillietina tunetensis & Leptotila verreauxi & Costa Rica & EU665487 & Davaineidae \\
\hline Raillietina sp.1 & Crax rubra & Costa Rica & EU665486 & Davaineidae \\
\hline Raillietina australis & Dromaius novaehollandiae & Australia & EU665484 & Davaineidae \\
\hline Taenia saginata & Homo sapiens & Kenya & AM503345 & Taeniidae \\
\hline Taenia hydatigena & Dog & China & HQ204207 & Taeniidae \\
\hline Taenia crassiceps & Canis lupus & France & JN849401 & Taeniidae \\
\hline Taenia regis & Panthera leo & Kenya & AM503348 & Taeniidae \\
\hline Hymenolepis diminuta & Rattus rattus & Spain & HM149291 & Hymenolepididae \\
\hline Hymenolepis sp. & Microtus socialis & Kazakhstan & HM149292 & Hymenolepididae \\
\hline Diphyllobothrium nihonkaiense ${ }^{b}$ & Canis lupus & Canada & HQ423296 & Diphyllobothriidae \\
\hline
\end{tabular}

${ }^{a}$ Query sequence generated.

bUsed as out group.

\section{RESULTS}

\section{LM and SEM observations}

Four species of Raillietina subjected in this study included $R$. echinobothrida, R. tetragona, R. cesticillus, and Raillietina sp. (a species undetermined). They were morphologically different (Figs. 1-5) which were summarized in Table 3.

\section{Sequence analysis}

The length of ITS2 regions were varied among Raillietina spp. In the case of ND1 gene, sequence derived from Raillietina spp. were the same in length. Our Raillietina ITS2 and ND1 sequences were aligned with other Raillietina species from GenBank and then were trimmed to provide an equivalent sequence. The result revealed several insertions and deletions in the 748 bp alignment of ITS2 sequence among Raillietina spp. For the ND1 alignment revealed 213 variable nucleotide sites (no gab) in the length of $468 \mathrm{bp}$. These variable sites including 45 purine transitions, 26 pyrimidine transitions, 66 transversions and 76 multiple changes. 
Table 3. Comparative morphology of Raillietina spp. found in domestic chickens in Thailand

\begin{tabular}{|c|c|c|c|c|}
\hline & Raillietina echinobothrida & Raillietina tetragona & Raillietina cesticillus & Raillietina sp. \\
\hline \multicolumn{5}{|l|}{ LM observation } \\
\hline Scolex shape & round & ovoid & nearly round & round \\
\hline Rostellum & armed & armed & armed & armed \\
\hline \multicolumn{5}{|l|}{ Rostellar hook } \\
\hline Row & 2 & 1 & 2 & 2 \\
\hline Shape & hammer-shaped & hammer-shaped & hammer-shaped & hammer-shaped \\
\hline Sucker shape & nearly round-shaped (armed) & ovoid-shaped (armed) & unarmed & round-shaped (armed) \\
\hline genital pore opening & unilateral & unilateral & irregularly alternating & unilateral \\
\hline Position of genital pore ${ }^{a}$ & P & A & A & A \\
\hline Number of egg/capsule & 8-12 & $6-12$ & 1 & 1 \\
\hline \multicolumn{5}{|l|}{ SEM observation } \\
\hline Rostellar opening surface & scale-like spines & scale-like spines & smooth & scale-like spines \\
\hline Strobila surface & pores & pores & pores & pores \\
\hline
\end{tabular}

aPosition of genital pore: $P=$ posterior to middle portion of each segment margin, $A=$ anterior to middle portion of each segment margin.

A

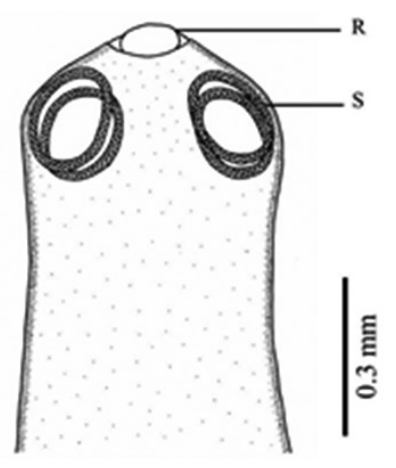

B
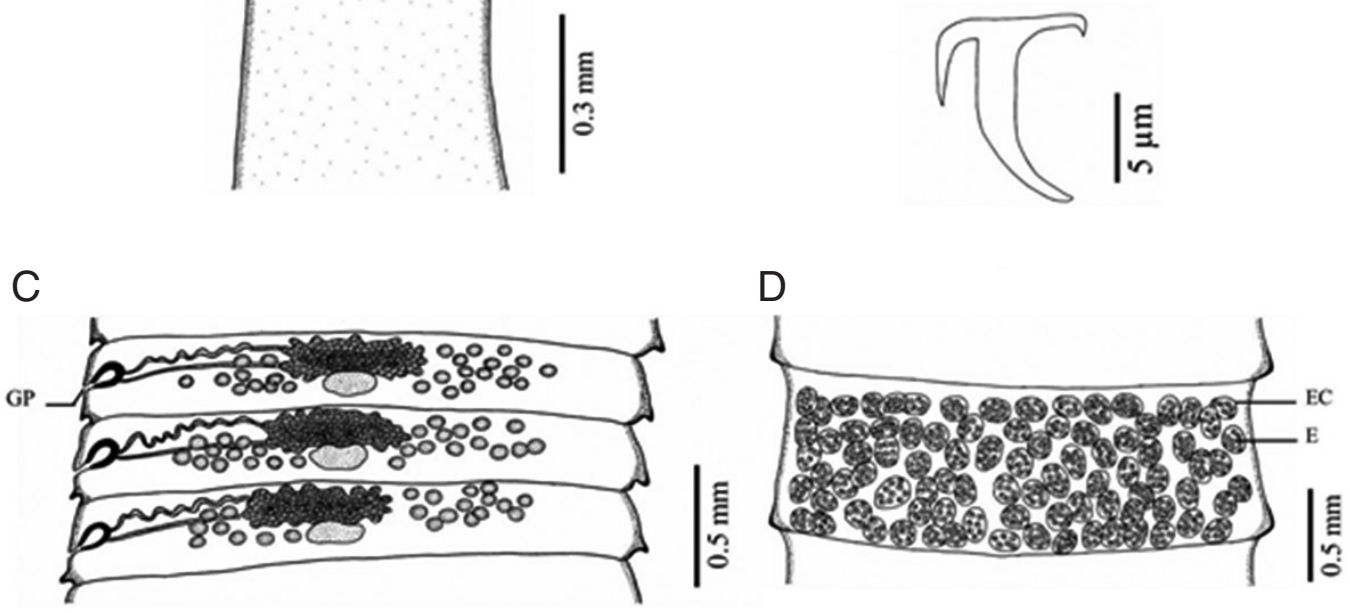

Fig. 1. Morphology of Raillietina echinobothrida. (A) Scolex bearing the rostellum (R) surrounded by 4 nearly round suckers (S). (B) Large hammer-shaped hook. (C) Mature proglottid showing unilateral opening of the genital pore (GP). (D) Gravid proglottid showing several eggs (E) per egg capsule (EC).

\section{Phylogenetic relationships based on ITS2 region}

The phylogenetic trees were reconstructed using NJ and ML methods (Fig. 6). The tree showed the most identical of tree topologies. This tree could be divided into 2 main clades; the first one was the helminth from order Cyclophyllidea, and the second one was the helminth from order Pseudophyllidea. The first clade was also divided into 2 subclades as the clade $\mathrm{A}$ that included all of Raillietina group, and the clade B that included the samples from the relative group. The Raillietina spp. group was monophyletic that had moderate bootstraps supported. Raillietina spp. were separated into 2 groups according to the number of eggs per egg capsule. R. echinobothrida and $R$. tetragona were grouped together with other Raillietina spp., while R. cesticillus and Raillietina sp. were in the same group.

\section{Phylogenetic relationship based on ND1 gene}

The phylogenetic trees were reconstructed using NJ and ML methods. The tree showed the most identical of tree topolo- 
A

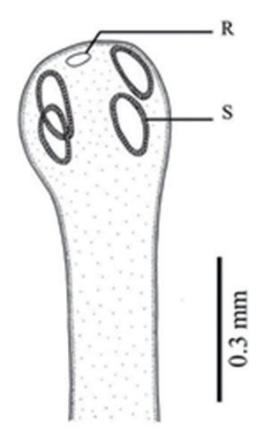

B<smiles>CCCCCCCCCCC</smiles>

C

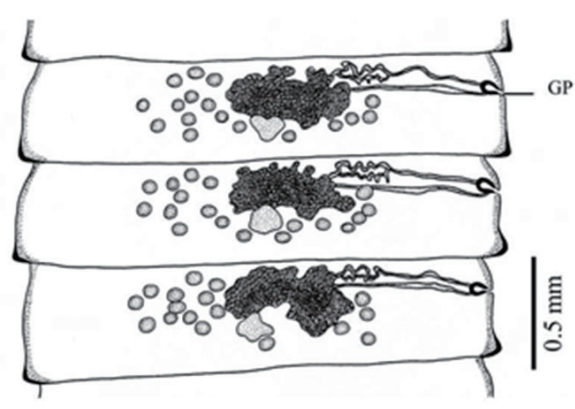

D

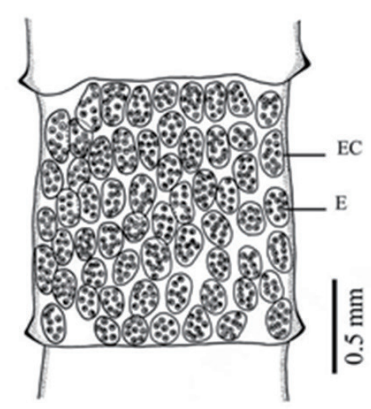

Fig. 2. Morphology of Raillietina tetragona. (A) Scolex bearing the rostellum (R) surrounded by 4 ovoid suckers (S). (B) Small hammershaped hook. (C) Mature proglottid showing unilateral opening of the genital pore (GP). (D) Gravid proglottid showing several eggs (E) per egg capsule (EC).

A

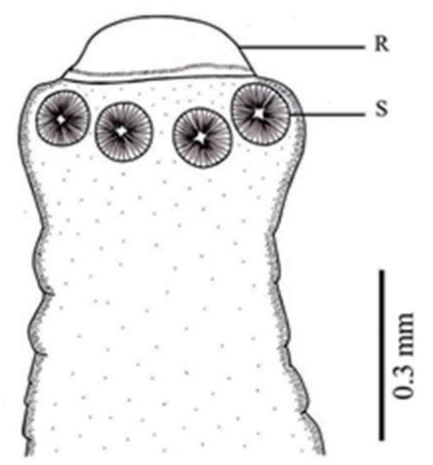

B

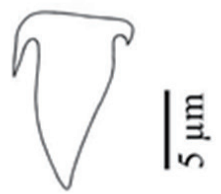

C

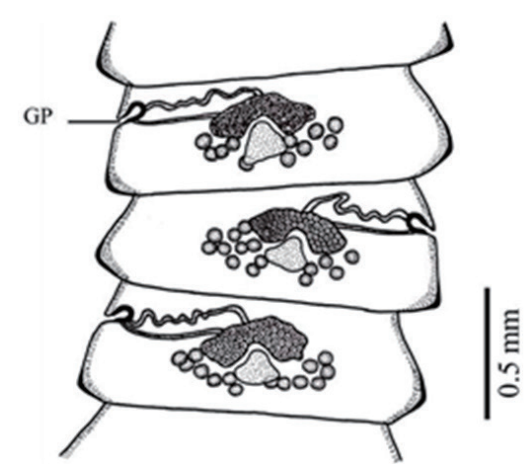

D

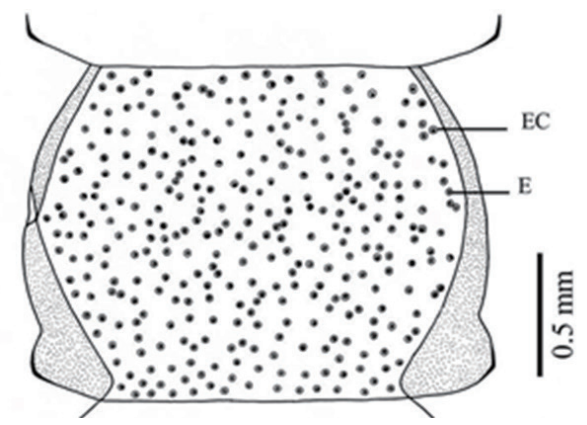

Fig. 3. Morphology of Raillietina cesticillus. (A) Scolex bearing the rostellum (R) surrounded by 4 unarmed round suckers (S). (B) Large hammer-shaped hook. (C) Mature proglottid showing irregularly alternating opening of the genital pore (GP). (D) Gravid proglottid showing a single egg (E) per egg capsule (EC). 
A

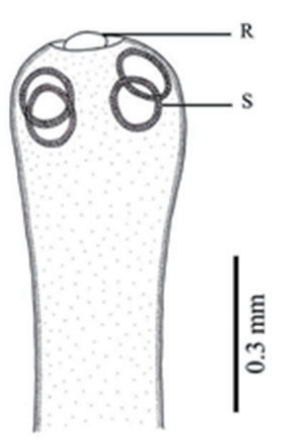

B

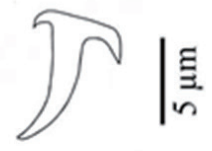

C
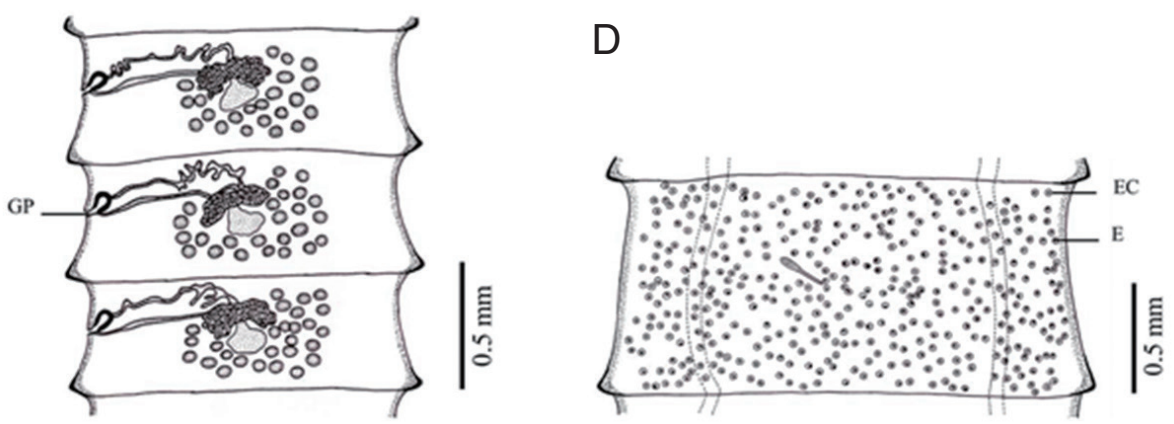

Fig. 4. Morphology of Raillietina sp. (A) Scolex bearing the rostellum (R) surrounded by 4 round suckers (S). (B) Small hammer-shaped hook. (C) Mature proglottid showing unilateral opening of the genital pore (GP). (D) Gravid proglottid showing a single egg (E) per egg capsule (EC).

gies as shown in Fig. 7. This tree could be divided into 2 main clades; the first clade was also divided into 2 subclades that were similar to the tree based on ITS2. The Raillietina group was monophyletic that had moderate bootstraps supported, and was separated into 3 groups according to unilateral and irregularly alternating openings of the genital pore and the number of eggs per egg capsule. These 3 groups included Raillietina sp. group, R. cesticillus group, and R. echinobothrida and $R$. tetragona which were grouped together with other Raillietina spp.

\section{DISCUSSION}

Based on LM observations, the morphological characters of Raillietina spp. in our study were similar to those of Hofstad et al. [4], Sawada [12], and Sawada [13]. The morphology of 4 Raillietina species was clearly different. The main features separating the species are the morphology of the scolex which differs in size and shape of the rostellum and suckers. R. echinobothrida and Raillietina sp. have round rostellum and nearly round and round suckers, respectively, while $R$. tetragona has small round rostellum and ovoid suckers, and $R$. cesticillus has large rostellum and suckers unarmed $[4,12,13]$. The rostellar hooks of $R$. tetragona are arranged in a single row while those of the 3 remaining species are arranged in 2 rows. Additionally, there are some more details revealing morphological dissimilarity. In R. echinobothrida, R. tetragona, and Raillietina sp., the genital pore is unilateral and situated in the posterior (R. echinobothrida), and anterior (R. tetragona, and Raillietina sp.) third portions of each segment, while in $R$. cesticillus it is irregularly alternating and situated in the anterior third portion of each segment. Moreover, R. echinobothrida and R. tetragona have several eggs per egg capsule within the gravid proglottid (8-12 and 6-12 eggs, respectively), whereas R. cesticillus and Raillietina sp. have a single egg per egg capsule. SEM observations showed the surface morphology of recovered Raillietina that was similar to previous studies [14-16]. The results revealed several pores on the body surface in all 4 species but different in the rostellar opening. R. echinobothrida, R. tetragona, and Raillietina sp. have scale-like spines along the edge of the opening, and only in $R$. cesticillus the edge is smooth.

Phylogenetic relationships of Raillietina spp. in domestic chickens from Thailand had not been studied before. The ribosomal DNA and mitochondrial genes have been widely used to identify and study phylogenetic relationships because 

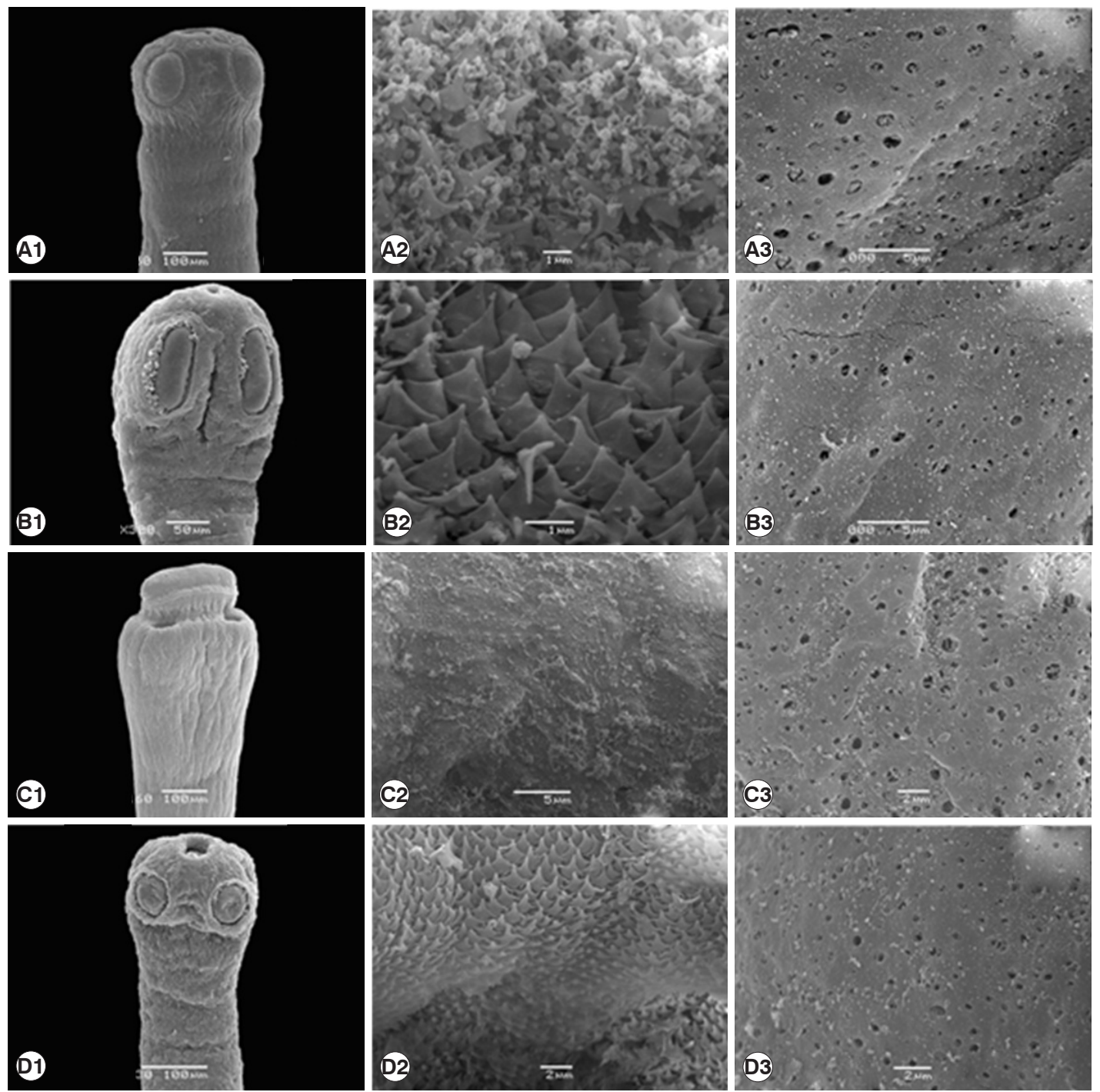

Fig. 5. SEM micrographs of 4 Raillietina species. (A) R. echinobothrida. (B) R. tetragona. (C) R. cesticillus. (D) Raillietina sp. (A1, B1, C1, D1) Scolex bearing the apical rostellum surrounded by 4 suckers. (A2, B2, D2) Rostellar opening revealing several scale-like spines along the edge. (C2) Rostellar opening revealing the smooth surface. (A3, B3, C3, D3) Strobila showing numerous pores on the surface.

they have fast evolutionary rates [17-19]. In our study, ITS2 and ND1 regions were successfully developed for studying the phylogenetic relationships of Raillietina spp. The results revealed that the ITS2 and ND1 sequence data recorded from Raillietina spp. appeared to be monophyletic. The bootstrapping of both trees indicated significant supports for grouping. These results were similar to previous studies $[7,20]$. The query sequences of R. echinobothrida, R. tetragona, R. cesticillus, and Raillietina sp. were aligned and placed within the Davaineidae group with other species of Raillietina, and separated from the Hymenolepididae and Taeniidae as a relative group, and also separated from the Diphyllobothridae as an out-group.
The phylogenetic trees derived from both ITS2 and ND1 sequence showed that each Raillietina was separated in correlation with the morphological characters and their definitive host. The phylogenetic relationships obtained using ITS2 sequences and the gravid proglottid characters could separate them into 2 groups. R. echinobothrida and $R$. tetragona were grouped together and closely related to other Raillietina species because of similarity in the egg number per egg capsule, i.e., several eggs in each capsule. R. cesticillus and Raillietina sp. had a single egg in each capsule and were grouped together. The phylogenetic relationships obtained from ND1 sequence showed a phylogenetic tree which differs from that based on 


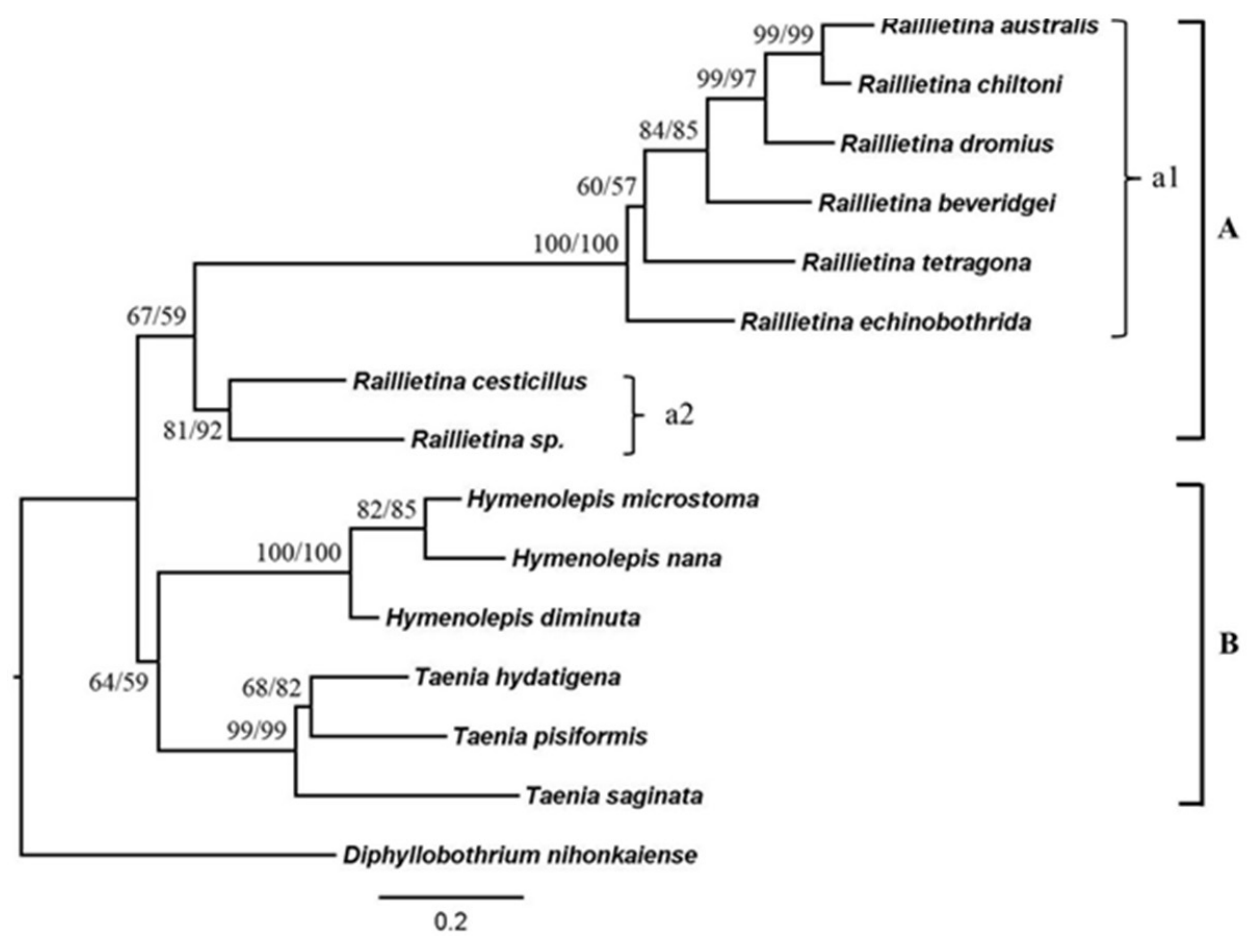

Fig. 6. Neighbor-joining (NJ) and maximum-likelihood (ML) bootstrap consensus tree with 1,000 bootstrap replicates of ITS2.

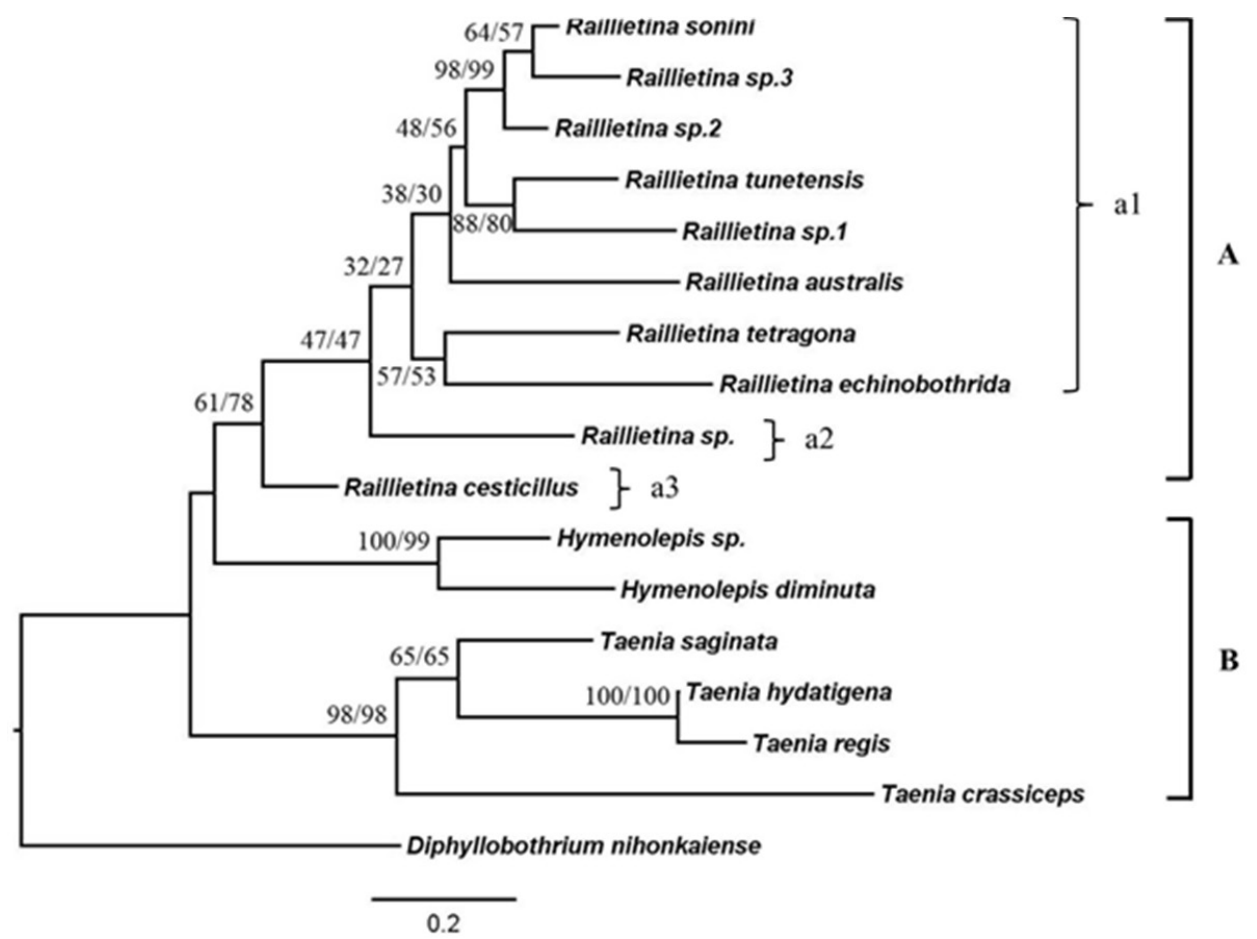

Fig. 7. Neighbor-joining (NJ) and maximum-likelihood (ML) bootstrap consensus tree with 1,000 bootstrap replicates of ND1.

ITS2 sequence. Each Raillietina species was separated according to the genital pore opening and the egg numbers in each egg capsule. The first group revealed unilateral genital opening and several eggs in each capsule, and included R. echinobothrida, $R$. 
tetragona, and other Raillietina species. The second group had unilateral genital opening and a single egg in each capsule, and included Raillietina sp., and another group which had an irregularly alternating opening and a single egg in each egg capsule, and included $R$. cesticillus. Raillietina sp. was separated from $R$. cesticillus because of the different genital pore opening, while it was grouped to be a sister taxa of the first group because they have some similar morphologies, including suckers armed, unilateral genital opening, and scale-like spines along the rim of the rostellar opening. Moreover, each Raillietina in 'a1' group of ITS2 and ND1 trees was separated according to their definitive host. For example, R. echinobothrida and R. tetragona are more related to each other than the other Raillietina spp. because their definitive host is domestic chickens whereas the other Raillietina spp. use other birds as their definitive host $[2,8,21]$.

Our study can conclude that the sequence data of ITS2 and ND1 regions combined with morphological observations using LM and SEM can be a useful tool for identification and understanding the phylogenetic relationships in the Raillietina group. Their relationships were defined according to the systematic criteria. Furthermore, the phylogenetic tree derived from ND1 sequence could separate the different morphologies of the genital pore opening (unilateral and irregularly alternating) because the evolution of the mitochondrial gene is faster than the nuclear gene.

\section{ACKNOWLEDGMENTS}

We would like to thank the Applied Parasitology Research Laboratory, Department of Biology, Faculty of Science, and the Science and Technology Research Institute, Chiang Mai University, Thailand for their assistance. Special thanks are extended to the Royal Golden Jubilee Ph.D. program scholarship and the Graduate School, Chiang Mai University, Thailand for their support.

\section{CONFLICT OF INTEREST}

We have no conflict of interest related to this study.

\section{REFERENCES}

1. Schmidt GD. Handbook of Tapeworm Identification. Boca Raton, Florida, USA. CRC Press, Inc. 1986, p 252-266.

2. Butboonchoo P, Wongsawad C. Occurrence and HAT-RAPD analysis of gastrointestinal helminths in domestic chickens (Gallus gallus domesticus) in Phayao province, northern Thailand. Saudi J Biol Sci 2015 (in press).

3. Permin A, Hansen JW. The Epidemiology, diagnosis and control of poultry parasites. A FAO Handbook. Food and Agriculture Organization of the United Nations, Rome, Italy. 2003, p 36-39.

4. Hofstad MS, Calnek BW, Helmboldt CF, Reid WM, Yoder HW. Diseases of Poultry. Iowa State University Press. 1984.

5. Alenyorege B, Alexander A, Kosono A, Addy S. Termites as intermediate hosts for poultry worms. J Vet Adv 2011; 1: 16-23.

6. Yamaguti S. Systema Helminthum. Vol. II. The Cestodes of Vertebrates. New York \& London. Interscience Publishers Inc. 1959, p 1-860.

7. Khalil LF, Jones A, Bray RA. Keys to the Cestode Parasites of Vertebrates. London, UK. International Institute of Parasitology. 2006, p 1-424.

8. Littlewood DTJ, Waeschenbach A, Nikolov PN. In search of mitochondrial marker for resolving the phylogeny of cyclophyllidean tapeworms (Platyhelminths, Cestode) - a test study with Davaineidae. Acta Parasitol 2008; 53: 133-144.

9. Okamoto M, Agatsuma T, Kurosawa T, Ito A. Phylogenetic relationship of three hymenolepidid species inferred from nuclear ribosomal and mitochondrial DNA sequences. Parasitology 1997; 115: 661-666.

10. Wickstrom LM, Haukisalmi V, Varis S, Hantula J, Henttonen H. Molecular phylogeny and systematics of anoplocephaline cestodes in rodents and lagomorphs. Syst Parasitol 2005; 62: 8399.

11. Lavikainen A, Haukislmi V, Lehtinen MJ, Henttonen H, Oksanen A, Meri S. A phylogeny of members of the family Taeniidae based on the mitochondrial cox1 and nad1 gene data. Parasitology 2008; 135: 1457-1467.

12. Sawada I. On the genus Raillietina Fuhrmann, 1920 (I). J Nara Gakugei Univ (Natural Science) 1964; 12: 19-36.

13. Sawada I. On the genus Raillietina Fuhrmann 1920 (II). J Nara Gakugei Univ (Natural Science) 1965; 13: 5-38.

14. Ilie MS, Darabus GH, Oprescu I, Morariu S, Mederle N, Ilie A, Imre K, Mandita D, Mederle O. The electron-microscopic characterization of some helminths found in birds. Lucrari Stiintifice Med Vet 2008; 41: 402-410.

15. Lalchhandama K. On the structure of Raillietina echinobothrida, the tapeworm of domestic fowl. Sci Vis 2009; (4): 174-182.

16. Kunda S, Lyndem LM. In vitro screening for cestocidal activity of three species of Cassis plants against the tapeworm Raillietina tetragona. J Helminthol 2013; 87: 154-159.

17. Xiao N, Qiu J, Nakao M, Li T, Yang W, Chen X, Schantz PM, Craig PS, Ito A. Echinococcus shiquicus n. sp., a taeniid cestode from Tibetan fox and plateau pika in China. Int J Parasitol 2005; 35: 693-701.

18. Malsawmtluangi C, Prasad PK, Biswal DK, Tandon V. Morphological and molecular identification of the metacestode parasitizing the liver of rodent hosts in bamboo growing areas of Mizoram, northeast India. Bioinformation 2011; 7: 393-399. 
19. Ghobashy MA, Taeleb AA. Molecular characterization of Raillietina (r.) spp. Ortlepp, 1938 (Cestode: Cyclophyllidea: Davaineidae) infecting domestic and wild bird (Columba livia and Columba livia domestica). World J Zool 2015; 10: 136-141.

20. Ramnath DB, Jyrwa DB, Dutta AK, Das B, Tandon V. Molecular characterization of the Indian poultry nodular tapeworm, Rail- lietina echinobothrida (Cestoda: Cyclophyllidea: Davaineidae) based on internal transcribed spacer 2 region. J Parasit Dis 2014; 38: 22-26.

21. O’ Callaghan MG, Davies M, Andrews RH. Species of Raillietina Fuhrmann, 1920 (Cestoda: Davaineidae) from the emu, Dromaius novaehollandiae. Trans R Soc S Aust 2000; 124: 105-116. 